\title{
La Universidad de Santiago de Compostela (1939-1969): de la indiferencia y la "no adhesión" al antifranquismo
}

\author{
University of Santiago de Compostela (1939-1969): \\ from the Indifference and "No Adhesion" \\ to the Antifrancoism
}

\author{
Ricardo Gurriarán Rodríguez ${ }^{*}$ \\ Universidad de Santiago de Compostela
}

Recibido: $\quad 19 / 02 / 2020$

Aceptado: $\quad 05 / 05 / 2020$

DOI: https://doi.org/10.20318/cian.2020.5430

Resumen: Este trabajo recoge los sucesivos cambios que se dieron en el solar universitario compostelano entre 1939 y 1969 , cómo se fueron propiciando y gestando desde dentro. Explica el escenario del período de limpieza y control de la victoria bélica, pasando por el yermo panorama de la década de los cincuenta, hasta los acontecimientos del año 1965, a los que luego se agregó la extensión del estallido emancipatorio y democrático de la juventud, en 1968. El avance de la confrontación en otros campus, de los que se importaron modelos, la coordinación y la organización efectiva, más el cambio de actitud de parte del profesorado, junto a la lucha sociopolítica general contra el franquismo, fueron determinantes para desgastar a la je-
Abstract: This work presents the successive changes that took place at the University of Santiago de Compostela between 1939 and 1969 and focuses on how this transformation was propitiated and gestating from within. It explains the circumstances of the period of purging and control of the military victory, continues with the barren panorama of the fifties, and goes on until the events of 1965 and later on, in 1968, the extension of the emancipatory and democratic outbreak of young. The increase of confrontation in other campuses, from where coordination and effective organization models were imported, the changing of attitude from part of the teaching staff, together with the general socio-political struggle against Francoism,

"ricardo.gurriaran.rodriguez@gmail.com 
rarquía franquista y lograr unos resultados esperanzadores con sintonía de cambio en todo el Estado, no sin dejar de pasar por una dura recesión con represión.

Palabras clave: SEU (Sindicato Español Universitario), "adhesión", negociación, cultura, represión. were decisive to wear down the Franco hierarchy. After suffering a recession with hard repression, encouraging results were achieved with a harmony of change.

Keywords: SEU (Spanish University Union), "adhesion", negotiation, culture, repression.

Desde el recuerdo compostelano a dos activos luchadores contra el franquismo y por la transformación democrática: Fermín Bouza y Vicente Álvarez Areces (in memoriam)

\section{Un distrito periférico respirando "tranquilidad"}

En la Universidad de Santiago de Compostela (USC), al igual que acontecía en el resto de los distritos universitarios españoles al finalizar la guerra civil, los organismos ocupados en la depuración, junto a las instituciones de control ideológico creadas por el nuevo Estado, se encargaron de "limpiar y pacificar" las aulas sin encontrar resistencias, como ocurría con los vencidos en todos los ámbitos de la administración. Al profesorado depurado que permaneció en la ciudad se le aplicaron sanciones ejemplares menores -traslados, separaciones temporales del servicio y, fundamentalmente, inhabilitación para desempeñar cargos de confianza- ${ }^{1}$. La inacción de los perdedores no adictos, por temor a represalias e indiferencia, fue la tónica dominante en el escenario posbélico, con la presencia de un Sindicato Español Universitario (SEU) que se abría paso intentando disputar terrenos de poder a las diferentes facciones políticas que se consideraban protagonistas de la "cruzada" y asumía el papel de vigilante de la condición de "suficiente adhesión" que debían tener y ejercer profesores y alumnos. La sospecha y control de los universitarios se convirtió en su obsesión permanente para mantener el orden. Este sindicato, único, por supuesto, y de afiliación obligatoria, estaba dirigido por la mocedad más fanática que había combatido en la guerra civil y a la que, después de la contienda, prácticamente se le regaló el título por los servicios prestados a la "causa nacional", mediante exámenes de "ardor patriótico y méritos de guerra".

${ }^{1}$ Ricardo Gurriarán, Ciencia e conciencia na Universidade de Santiago (1900-1940). Do influxo institucionista e a JAE á depuración do profesorado (Santiago de Compostela, USC, 2006): 589-683. 
Queremos recordar que la institución universitaria compostelana mantenía el número de matriculados que heredara del período previo a 1936, tres mil. Esta cifra no aumentaría hasta la década de 1960. En la mayoría del profesorado local, el apoliticismo de otro tiempo se había convertido en fervor patriótico por el "movimiento liberador". También recaló en Compostela una buena representación de cualificados militantes del Opus Dei y algunos profesores "sospechosos", depurados y desterrados de sus lugares de origen (Prieto Bances, Barcia Trelles...).

Después del "atroz desmoche" que supuso el exilio y el apartamiento de docentes, muchas cátedras salieron a oposición ${ }^{2}$. La suficiente adhesión a la causa del nuevo Estado fue principal mérito para lograr una cátedra y venir a la periferia galaica como transición para ocupar destinos próximos a los lugares de decisión y poder, a veces tomando posesión y marchando ya. El resto del profesorado, en sus escalas más bajas, se cubría por afinidad ideológica y clientelismo.

Esta dinámica posbélica implantada por el llamado Nuevo Estado, de aparente pacificación, no impidió que en el gobierno uniformador de la universidad compostelana hubiese problemas. En todos los distritos, el equipo rectoral, como institución, era un eslabón más en la actuación legitimadora del Régimen. Pues bien, en 1942, la prensa local inicia una campaña de denuncia en la que se criticaba la falta de "ardor guerrero" del profesorado en el ejercicio de su misión formadora. Un día de enero de aquel año, el editorial del diario El Compostelano empezaba así: "La Universidad no responde hoy a nuestro sentir, a nuestro estilo y a nuestro nervio. La Revolución Nacionalsindicalista no ha logrado triunfar aún sobre el viejo liberalismo que invade cátedras y maestros. Aún bien reciente voces disidentes dentro de la calma chicha docente, se han alzado en demanda de la extirpación de este estado de cosas. La Universidad debe ser un vivero de mandos y escuela de formación falangista". Concluía arremetiendo contra las cátedras y su labor con los nuevos estudiantes, que se alejaban de "la emoción histórica que tuvieron los del 18 de julio de 1936". El rector Ruiz del Castillo, catalogado por el SEU de proceder antirreflexivo y antifalangista, estaba en el ojo del huracán. Los sindicalistas indicaban la conveniencia de su relevo, "por bien de la Falange" ${ }^{3}$.

${ }^{2}$ La frase "atroz desmoche" fue utilizada por el profesor Laín Entralgo para referirse a la represión universitaria, en su ejercicio de palinodia Descargo de conciencia (1976), que luego dio título al magnífico trabajo del profesor Jaume Claret.

${ }^{3}$ José Ramón Rodríguez Lago, La Iglesia en la Galicia del franquismo (Sada, A Coruña, Ediciós do Castro, 2005): 512 y 513. 
En la primavera de aquel año, la universidad gallega vivió -como en otros distritos-altercados violentos entre facciones políticas: el seuísmo recalcitrante, con apoyo de la estructura política local, se revolvía ante el resurgimiento del juanismo (defensores de la vuelta a la monarquía, que encabezaba don Juan); por su parte, el falangismo ortodoxo y la cúpula franquista "unificada" protagonizaban sus propias luchas por el poder. El resultado de este conflicto fue la destitución del rector Carlos Ruiz del Castillo y Catalán de Ocón, comenzando el curso 1942/43, enmarcada en las tentativas restauradoras de los monárquicos y un enfrentamiento directo entre el rector y el SEU más violento, que incluso convocó una manifestación en su contra, después de que los representantes del sindicato universitario se negaran a retirar su propaganda falangista del edificio central de la Universidad entre gritos de ¡fuera el Rector! y cánticos falangistas ${ }^{4}$. En el mes de mayo la Universidad permaneció unos días cerrada. En agosto, el máximo dirigente falangista de la provincia, Salas Pombo, recomendaba el cambio de rector, después de emitir un comentario acerca de su labor docente: "En su cátedra de Derecho Político ha seguido prestando una extraordinaria atención a los regímenes liberales de los que se muestra ferviente admirador en sus explicaciones de cátedra"5.

Carlos Ruiz del Castillo, de pasado monárquico, al igual que su mentor el ministro Sainz Rodríguez, fue substituido por el camisa vieja Luis Legaz Lacambra, también catedrático de Derecho, jefe comarcal de Falange desde 1940 y manifiesto discrepante del rector cesado, desde tiempo atrás. El Régimen se encargó de no hacer mucho ruido para resolver la sucesión y de recolocar en Madrid al destituido. También en el Ayuntamiento de Santiago se produjo un cambio de gestor municipal para substituir al alcalde Gil Armada, otro monárquico. El conflicto se enmarcaba en las luchas internas por el reparto ministerial y el poder territorial.

Sobre la otra orilla ideológica del estudiantado, en un exceso de celo y magnificando la realidad, un documento informativo de responsables del SEU de 1946 afirmaba la presencia en Santiago de grupos de estudiantes "peligrosos", dirigidos por el profesor Alonso Zamora Vicente: “También son una realidad dentro del recinto universitario los núcleos masónicos, peligrosísimos, a nuestro parecer: en lo que respecta a ellos, están integrados,

\footnotetext{
${ }^{4}$ Ricardo Gurriarán, Inmunda escoria. A universidade franquista e as mobilizacións estudantís en Compostela, 1939-1968 (Vigo, Edicións Xerais, 2010): 63-68.

${ }^{5}$ Emilio Grandío Seoane, "Dereita e rexionalismo galego na II República: Carlos Ruíz del Castillo", Grial 34 (abril-junio, 1997): 191.
} 
seguramente, por estudiantes que en muchos casos no conocen servir a la Masonería, sino al Catedrático o auxiliar que le dispensa un trato más cordial y afectuoso que la mayor parte del profesorado, y que hace que el estudiante sirva de instrumento, en muchos casos, inconsciente, pero útil”. Acaba añadiendo la localización de un grupo de las características descritas en el Colegio Mayor Generalísimo Franco, durante el curso anterior. Eran los destellos pedagógicos de institucionismo que irradiaba la metodología activa del profesor Zamora Vicente, profundamente liberal, que vivía y convivía en aquel colegio con profesores deportados y alumnos con ganas de saber y participar ${ }^{7}$. La convivencia en este centro se ampliaba a veces con estancias temporales de profesores alemanes, italianos y portugueses.

La cosa no pasó del informe del SEU. Los colegios mayores estaban llamados a ser el principal núcleo formativo de las futuras élites dirigentes, según su decreto regulador ( 9 de marzo de 1942) que, entre otros fines, pretendía: "Ejercer sobre los escolares una tutela que, combinada con un régimen de libertad vigilada, se proponga la formación de su carácter y el desarrollo de todas sus facultades bajo los principios de la Iglesia Católica". Con el paso del tiempo, estos centros se convertirían en importantes núcleos de disidencia antifranquista.

Sin embargo, en 1947, algunos profesores de ideología liberal y antifranquista fueron detenidos por tener contactos clandestinos con la Unión de Intelectuales Libres y con el Socorro Rojo, según la acusación, que afectó a un grupo de dieciocho encausados. Es posible que tuviesen afinidad con estas organizaciones y que algunos médicos procesados, a la vez docentes de la Facultad de Medicina, ayudasen a la guerrilla y a sus familias perseguidas, pero nunca se demostró que así fuera. El caso es que los profesores Ulpiano Villanueva y Ramón Baltar estuvieron una corta estancia en la cárcel de Vigo. Fueron procesados por el Tribunal Especial para la Represión de la Masonería y el Comunismo (causa no 438/47). Lo único que habían detectado los servicios de información franquistas era la poca sintonía de algunos profesores con lo que estaba aconteciendo a su alrededor, que se reunían y, probablemente, que hacían públicas sus discrepancias. Este proceso tuvo

\footnotetext{
${ }^{6}$ Agradecemos a la profesora Elena Hernández Sandoica la cesión de este documento procedente del archivo personal del dirigente seuísta José María del Moral (jefe Nacional del SEU desde 1947). Está firmado en 21 de octubre de 1946 por los responsables del SEU santiagués José Luis Taboada García (jefe de Distrito desde 1942) y José Rubio Rivas.

${ }^{7}$ El profesor Alonso Zamora Vicente dejó escrita su huella en el Santiago de los años cuarenta en la publicación memorialista Compostela, años atrás (Santiago de Compostela, USC y Consorcio de Santiago, 1993).
} 
mucha repercusión entre la docencia universitaria y la sociedad santiaguesa, a pesar de que los órganos represivos fueron discretos en sus acciones.

En cuanto al estudiantado en esta década, no tenemos más que algunas referencias dispersas y poco concretas de acciones propagandísticas de disidencia. La primera, que proviene de los servicios de información franquista, da cuenta de unas hojas volantes lanzadas por estudiantes de la USC en 1942 y firmadas por la FUE en las que se recuerda la labor de este sindicato estudiantil durante el período republicano ${ }^{8}$. Según las fuentes, el hecho llegó a pocos estudiantes y apenas trascendió.

Desde las navidades del curso 1948/49, tenemos la presencia de un grupo que se hace llamar Comité de Estudiantes Universitarios. Había editado tres hojas volantes escritas en gallego y lanzadas en un período de cinco meses; en ellas denunciaban la situación económica y política que vivía España -"callejón sin salida" - y recogían algún episodio de la "gloriosa historia de Galicia". Aparte de elementos históricos y políticos, hacían referencia al irrespirable clima y a la represión que se vivía en aquellos momentos, al tiempo que realizaban un llamamiento a la difusión de aquellas hojas, extremando las cautelas de seguridad que debían seguirse para su entrega ${ }^{9}$.

El investigador alemán Hartmut Heine, especialista pionero del período franquista en Galicia, asegura que este grupo tenía relación con la tentativa de reconstruir en la universidad gallega las Mocedades Galeguistas, rama juvenil del Partido Galeguista ${ }^{10}$.

\section{La politización de las aulas comienza en Madrid (1951-1956)}

Apatía y apartamiento de las consignas de la jerarquía del SEU fueron las principales características de buena parte del estudiantado en los años cincuenta. La pretensión de que la mayoría social de universitarios siguiese las esencias y preceptos emanados de la "victoria" comenzaba a esfumarse, tras una década de obsesivo control ideológico del estudiantado por parte de los responsables seuístas, mediante el acoso adoctrinador con principios revolucionarios nacionalsindicalistas.

${ }^{8}$ VV. AA. Documentos inéditos para la Historia del Generalísimo Franco (Madrid, Fundación Nacional Francisco Franco, Tomo III): 426.

${ }^{9}$ Estas hojas están depositadas en el archivo de la Fundación Xaime Isla, Vigo (sin clasificar).

${ }^{10}$ Hartmut Heine, A guerrilla antifranquista en Galicia (Vigo, Edicións Xerais, 1980): 254-255. 
Las aulas preñadas de iconografía de la victoria, los alumnos uniformados con correajes y armas, también algún profesor, completaban el escenario material de la primera época, donde los actos oficiales y los de propaganda, mezclados, ocupaban lugar principal -Día del Estudiante Caído, Santo Tomás, San Isidoro, de la creación del SEU, del Licenciado, de África, comienzo de Curso, Hispanidad...-. El poder y el control ideológico del SEU comenzaba a desmoronarse entre el estudiantado compostelano, en gran medida ayudado por los ecos del desencanto de una parte de dirigentes falangistas que comenzaban a disentir. Consecuentemente, la reorientación del sindicato fue inevitable ante el declive. De las tareas de agitación y adoctrinamiento que venía ejerciendo, la cúpula dirigente pasó a visibilizarse ejerciendo labores de organización y prestación de servicios, y de suministro de cierta cultura -que era control también-: una progresiva burocratización para atraer a la masa estudiantil "indiferente"; de forma clientelar, otorgaban becas de estudio y de acceso a los colegios mayores, viajes al extranjero...

La llegada al Ministerio del propagandista católico Ruiz-Giménez, de la congregación mariana ACNP, dio aires nuevos a la gestión y a las aulas, con la rehabilitación de algunos profesores apartados y otros exiliados que se reincorporaban a la docencia y con la elección de cargos no connotados excesivamente con el partido único. En Madrid, el activismo estudiantil se organizaba con el laissez faire de algunos profesores universitarios que ocupaban cargos directivos de gestión. Cierta autonomía parecía un espejismo, pero el aperturismo ministerial tan sólo duró hasta 1956, no sin antes entrar España en la UNESCO (1952) y la ONU (1955), requisitos imprescindibles para formar parte del escenario político internacional, después de la derrota del eje ${ }^{11}$.

El acceso libre del estudiantado a la cultura y sus propuestas de participación y de organización, fuera de corsés censores y de control, eran reivindicaciones que comenzaban a cobrar relevancia. Las demandas de libertad se convirtieron en principal objeto del estudiantado para oponerse al Régimen. En cuanto a los procedimientos, no hay que olvidar la consigna de penetración en todos los tejidos sociales -incluidos el SEU y otros organismos oficiales-, que tan buenos resultados le dio al PCE. En aquel período comenzó la politización de una juventud hastiada de consignas y de fundamentos trasno-

${ }^{11}$ Sobre la estrategia política del franquismo para acercarse a las instituciones internacionales, con el nacionalcatolicismo como bandera y nuevos políticos jóvenes ejerciendo en ministerios claves, después de la II Guerra Mundial, ver Ricardo Gurriarán "A Asociación de Cultura Iberoamericana da Coruña (ACI) e O Facho: cultura asociativa no franquismo, con Fraga na rebotica", en A cultura e o asociacionismo cívico na Coruña. Entre a oficialidade e a resistencia, ed. Ricardo Gurriarán (Fundación 10 de Marzo y Concello da Coruña, 2019): 127-159. 
chados, en buena medida catalizada por la presencia en España de militancia comunista que se había trasladado desde París para organizarse en el interior y por la emergencia del FELIPE y de los socialistas de la ASU, y otros grupos cristianos que actuaban en los principales distritos universitarios.

El estudiantado madrileño, andaluz y catalán empezaba a verse en la calle en las primeras movilizaciones de protesta contra el Régimen. También la intelectualidad no afín comenzaba a emitir juicios contra el orden "establecido", incluso desde publicaciones oficiales. Y a colaborar en semanas pedagógicas, cátedras y seminarios. Aparecen nuevas revistas donde el realismo social y el humanismo cristiano van cobrando fuerza en el ámbito de la disidencia; esta intervención en iniciativas culturales es una herramienta de toma de conciencia para emprender la acción política.

En este marco de tímida apertura afloran las tertulias, donde intercambian ideas estudiantes concienciados e intelectuales disidentes con efluvios liberales y republicanos. Por otra parte, el Opus Dei y la Falange inician una contraofensiva en los ámbitos de la cultura oficial frente a la "apertura democristiana”, que acabó con la destitución de la cúpula del Ministerio de Educación mientras en la universidad y en las calles madrileñas los estudiantes se manifestaban pidiendo libertad y en contra del SEU. Corría febrero de 1956. Ruiz-Giménez era cesado y la Universidad madrileña se cerraba después de altercados y doscientas detenciones. La respuesta pidiendo su libertad comenzó con un escrito de firmas dirigido al ministro, encabezado por Menéndez Pidal. Franco acababa de alertar del peligro comunista en el mensaje navideño de 1955: "El libertinaje de las ondas y de la letra impresa vuela por los espacios, y los aires de fuera penetran por nuestras ventanas, viciando la pureza de nuestro ambiente"12.

En aquel ambiente comenzaran a aflorar actos culturales con aroma de conciencia social y demandas de cambios políticos, como las Semanas de Renovación o los Encuentros entre la Poesía y la Universidad, iniciativas desarrolladas luego en otros distritos. 0 la aparición del Servicio Universitario del Trabajo (SUT, 1952) del Padre Llanos, principal escuela de cuadros políticos de la oposición al Régimen, partiendo de la toma de contacto con la realidad sociolaboral y su posterior reorientación, tras la pérdida progresiva del control del SEU ${ }^{13}$. Grupos de teatro, cineclubs y otras iniciativas tomaban

${ }^{12}$ Citado en Pablo Lizcano, La generación del 56. La Universidad contra Franco (Barcelona, Editorial Grijalbo, 1981): 134.

${ }^{13} \mathrm{Un}$ importante trabajo sobre las actividades de esta iniciativa se ha publicado recientemente en un documental de Andrés Armas y Miguel Ángel Nieto, realizado por Carlos G. Ayuso, reproducido en soporte DVD, Reflexiones alrededor de la Transición silenciada (Madrid, 
cuerpo y eran blanco de la censura oficial y paraoficial, cuando los estudiantes querían organizar actos sin imposiciones ni injerencias: con la cultura, la agitación estaba en marcha. Y el SEU empezaba a ver como sus candidatos eran derrotados en las elecciones de representantes.

\section{Cambios sin mudanza aparente en el distrito}

Si bien los acontecimientos universitarios de Madrid de 1956 no repercutieron directamente en Compostela, la llegada de algunos profesores desencantados con la senda que tomaba el franquismo sí llamó la atención en la Universidad y en la ciudad, a pesar del panorama que describía Franco Grande, estudiante de Derecho en aquel tiempo: "La realidad universitaria era aplastante. Lo era doblemente: el profesorado fue mi primera y gran decepción compostelana. No eran sólo malos, es que eran ridículos y, a veces, impresentables. Y aún peor los compañeros -y compañeras, que eran la mayoría- sólo preocupados de saber los programas"14. Atonía, vulgaridad e inercia, efectivamente, caracterizaban al estudiantado compostelano.

La presencia de los Carlos París y Alonso del Real (ambos en la Facultad de Filosofía y Letras) introdujo un cierto nuevo aire a la vieja universidad, que luego se completó con catedráticos de espíritu abierto que no habían participado en la guerra civil, como Lucas Verdú (Derecho), De Miguel Alonso (Derecho) y Núñez Puertas (Medicina), hijo de un notario salmantino represaliado, y el exiliado retornado Moreno Báez (Letras). De la misma forma que aconteciera en los distritos más avanzados, los estudiantes santiagueses comienzan a hacerle frente al SEU en las elecciones a representantes, en este caso provenientes de Acción Católica (AC), impulsados por unos consiliarios en sintonía con la renovación y la acción social que empezaba a hacerse visible desde los movimientos especializados. Y con la llegada a Santiago del nuevo arzobispo Quiroga Palacios, que empezaba su mandato enviando un telegrama de condolencia por la muerte de Castelao en el exilio ${ }^{15}$.

Diagrama Producciones S. L. y Azulmedia Audiovisual, 2017), que contiene un folleto explicativo con artículos de Andrés Armas, Juan Anllo y Miguel Ángel Ruiz Carnicer.

${ }^{14}$ Xosé Luís Franco Grande, Os anos escuros (Vigo, Edicións Xerais, 1985), tomo I: 23.

${ }^{15}$ Fernando Quiroga Palacios fue nombrado cardenal en 1952. Conoció a Juan XXIII en 1954, con motivo del Año Santo Compostelano. Entre sus preocupaciones destacaba el apostolado seglar y el contacto con la realidad más próxima. Con el rector Legaz mantuvo una excelente relación. Con una habilidad especial y una relación ambigua con el poder, desde la concordia, defendió la utilización del gallego en la liturgia. En el lado opuesto, fue connivente 
Mientras, el rector Legaz se adaptaba a los nuevos "designios" ministeriales, sin inmutarse y echando mano del paternalismo como bandera de relación con el alumnado, que él mismo caracterizaba de dócil y sumiso ${ }^{16}$. Otro prócer del galleguismo, Ramón Otero Pedrayo, retornaba a la docencia, en este caso universitaria, luego de enfrentarse a una nueva oposición, tras verse desprovisto de su cátedra en el instituto de Ourense durante diez años por sanción de los organismos depuradores.

Contrariamente a lo que había acontecido en la década anterior, el rector, con el SEU sometido al poder académico, iniciaba una cierta desfalangistización de tono liberalizante, acorde con la gestión del nuevo ministro RuizGiménez, a la par que controlaba los hilos del poder político de Compostela, gobernada por un alcalde que era catedrático de la Universidad. Al tiempo, Legaz iniciaba una labor cultural desde arriba, contando con el profesorado más activo, entre los que sobresalen los catedráticos recién llegados. Uno de ellos, Carlos París, comentaba su metodología contemplativa en la gestión de este modo: "Es que la clave para mantenerse en el poder aquellos años -y quizá también en gran medida en los actuales- no era la eficacia, sino el no crear problemas, dejándolos dormir. Y en esto el rector de la Universidad Compostelana era un maestro"17. Los equilibrios fueron su arma para armonizar a las familias que buscaban espacios de poder. El Opus, mientras no abrió en Pamplona su centro universitario, y en tanto el futuro rey no precisó preceptores, contó en el distrito de Santiago con buenos cuadros desde la llegada de los catedráticos de Derecho Amadeo de Fuenmayor y Laureano López Rodó en 1944 y 1945; y luego Federico Suárez Verdaguer, Ángel López-Amo y Álvaro d'Ors y Pérez-Peix, entre aquellos. Pues bien, representatividad institucional, impartición de cursos, cargos... eran hábilmente distribuidos por el rector, por "familias" y en dosis equitativas. También tenemos que reseñar las estadías en Compostela del filósofo y jurista nazi Carl Schmitt -después de librarse hábilmente del Juicio de Nüremberg-, que fue muy bien recibido por la intelectualidad profesoral universitaria de Santiago.

Entre la abulia y la inercia, con corbata y chaqueta obligada como uniforme para asistir a clase, significamos la preocupación cultural y lingüística que el veterano militante galleguista Ramón Piñeiro infundió a un grupo de universitarios ávidos de cultura e inquietudes dinámicas, con base formativa

en el regalo de las estatuas del maestro Mateo, procedentes del Pórtico de la Gloria, a "la casa del Pardo y señores de Meirás", que hizo el Ayuntamiento de Santiago a los Franco.

${ }^{16}$ Gurriarán, Inmunda: 100.

${ }^{17}$ Carlos París Amador, Memorias sobre medio siglo. De la contrarreforma a internet (Barcelona, Península, 2006): 92. 
en la mesa camilla de su casa. Antes ya recalaran en alguna de las tertulias que había en Compostela, encabezadas por alguno de los "santones galleguistas", sobre todo docentes como Otero Pedrayo y Río Barxa, el magistrado Bouza Brey, el pintor Carlos Maside, el doctor García Sabell... y la colaboración de los profesores de Magisterio Gonzalo Anaya y Alonso Montero. Entre el estudiantado "avanzado" predominaban los hijos de familias de tradición republicana y galleguista, fundamentalmente de maestros y exseminaristas. El galleguismo político, débil de estructura, había decidido iniciar una estrategia culturalista de resistencia desde 1950, con la Editorial Galaxia (Vigo) y los jóvenes universitarios como principales propuestas de intervención, dirigida a las élites.

De los discípulos de Ramón Piñeiro comenzaron a surgir acciones para incorporar la lengua gallega a la "oficialidad". Entre estas actividades, la más significada fue la inclusión del gallego entre las categorías del concurso de poesía anual que organizaba el SEU, reconvirtiendo los Juegos Florales en Fiestas Minervales (1956). También comandaban propuestas seuístas como La Tribuna del Estudiante o ciclos de conferencias bajo la denominación "Estudios Políticos" y colaboraban en la prensa universitaria del SEU y en la local, especialmente en el suplemento dedicado a Galicia del periódico La Noche. Fue el comienzo de una apertura posibilista de espacios al gallego, sin riesgo. En aquel yermo panorama cultural, estos "mozos", como les llamaba Piñeiro, formalizaron una irradiación de concienciación galleguista, constituyendo el principal antecedente de lo que habían de ser propuestas políticas nacionalistas en la década posterior. Entre sus herramientas contaban con la impartición de clases de gallego, organización de encuentros de poesía, conferencias y actos de afirmación patriótica e identitaria, traducciones varias de textos clásicos...

En el lado del profesorado, el citado Carlos París caracterizaba a la sociedad compostelana de tradición conservadora y añadía que la Universidad era ajena a cualquier vibración política ${ }^{18}$. Este catedrático de Fundamentos de la Filosofía desde 1951, de viraje ideológico radical, al año de llegar ya ejercía la principal responsabilidad cultural en la institución universitaria. Escribía artículos desde el noroeste en los que expresaba descontento con el presente y denunciaba la corrupción desde la "pureza revolucionaria jonsista". Aquí dirigía el Colegio Mayor San Clemente entre enfrentamientos constantes con los mandos del SEU, que trataban de desprestigiar su autoridad. En su sede organizó debates culturales y políticos impensables para la época. Desde la

\footnotetext{
${ }^{18}$ París, Memorias: 36.
} 
conmemoración del centenario del Origen de las especies de Darwin (1959), con el proscrito Faustino Cordón, a un ciclo de marxismo en el que contó con el aperturista en aquel tiempo Guerra Campos, encargado del nexo universitario con la Iglesia y canónigo desde 1951. Por aquel Colegio Mayor también pasaron conferenciantes de la talla de Bardem, Alfonso Sastre, Eva Forest y José María Valverde, que dejaron honda huella entre los colegiales. París fomentó la lectura y el deporte entre los universitarios y colaboró con el SUT en tareas sociales. Su homónimo Alonso del Real fue así mismo un activo docente de la Facultad de Filosofía y Letras, principal foco de cultura heterodoxa. Este catedrático de Prehistoria llegado en 1955, también caracterizaba públicamente a la USC como débil socialmente y políticamente nula ${ }^{19}$. Era capaz de disertar al alumnado asistente con conferencias sobre historiadores "fuera del índice" como Américo Castro o Sánchez Albornoz, o conmemorar aniversarios como la Revolución rusa. En esta nómina no podemos dejar a un lado al liberal democristiano Enrique Moreno Báez, formado en el Centro de Estudios Históricos antes de 1936, que participó en la extensión cultural. Este catedrático permaneció en Oxford hasta su retorno en 1949, donde había ido a ampliar estudios antes de la guerra civil.

En Derecho destacamos a Pablo Lucas Verdú, pionero en el cineclubismo universitario en Salamanca. Venía de la escuela funcionalista salmantina con Elías Díaz, Tierno Galván, Pedro Vega, Raúl Morodo... embrión socialista. Después, aquí participó en sesiones del Cineclub Universitario y organizó interesantes seminarios sobre europeísmo. Desde 1952, el SEU reconvertía la Fiesta del Estudiante en la Semana Universitaria, que paralelamente se complementaba con un festival de chanzonetas para criticar a la institución y a los profesores. Entre danzas de la Sección Femenina y alguna representación del TEU local, más alguna conferencia de profesores, se celebraban los citados Juegos Florales "de carácter nacional", con la presencia de jerarcas del SEU. Tras celebrarse en Santiago las Primeras Conversaciones Cinematográficas Nacionales, se creó un cineclub (1955), de funcionamiento irregular -desde el año anterior funcionaba el Cineclub Fonseca de AC-. También se puso en marcha el ya citado SUT, lo que sirvió para que los estudiantes santiagueses tuviesen una cierta movilidad y conociesen realidades diferentes acudiendo a campos de trabajo por España o logrando bolsas para ir al extranjero ${ }^{20}$.

\footnotetext{
${ }^{19}$ En entrevista realizada por Daniel Sueiro en la revista Alcalá n.o 68, de marzo de 1955.

${ }^{20}$ En Galicia, durante los doce años que duró la actividad del SUT, se organizaron 50 campos de trabajo en muy diversos sectores: pesca, industria conservera, química, cerámica, astilleros y dos campañas de educación popular, Ourense y Pontevedra en 1954 y Lugo en 1966. En Santiago de Compostela, los estudiantes desarrollaron actividades de atención sanitaria, educativa
} 
En 1954, sin tener una expresión política organizada, los estudiantes de Compostela desencadenaron algunas alteraciones académicas con repercusión en la ciudad. Primero fue contra una desafortunada nota de prensa de los jesuitas dirigida a las madres de chicas que acudían a los bailes "donde vendían su carne". Los cristales de la residencia que poseía la orden se vieron seriamente dañados por tratar de imponer una censura moral más. Aquel curso también vio como los estudiantes de Derecho se lanzaban a una huelga, muy secundada durante varios días, para echar a un profesor que abusaba del principio de autoridad. El rector acabó apartándolo temporalmente. Los conocidos Gonzalo Rodríguez Mourullo y Xosé Manuel Beiras andaban a la cabeza de esta "asonada". Incluso, por aquel entonces, los estudiantes, convocados por el SEU, elevaron protestas callejeras por la subida del precio de los cines cuando aún el empedrado de Compostela estaba caliente por la protesta contra la reina Isabel II que había visitado Gibraltar. Enfervorecidos, gritaron en la Plaza del Obradoiro: Gibraltar español.

En aquel 1954 se dieron algunas muestras de descontento espontáneo contra el SEU por parte de estudiantes. Durante los festejos de la III Semana Universitaria, se colocaron unas hojas informativas en las facultades con la convocatoria de una manifestación en protesta contra el cobro por entrar a los actos organizados de la Semana. Los jerarcas del SEU intentaron enseguida desactivar la protesta emplazando a los representantes del alumnado a una reunión, que la abandonaron sin resultado y persistieron en su postura. La manifestación recorrió el trayecto desde la Plaza de la Quintana hasta el edificio central de la Universidad, donde se iba a celebrar el acto oficial con todas las autoridades presentes. Ya dentro del edificio, los estudiantes trataron de entrar en el Paraninfo gritando: "Todo gratis"; los jefes del SEU les impidieron el acceso y los gritos se volvieron contra ellos con lindezas como: chulos, muera Fausto, muera Tahoces (ambos jefes del SEU local), chupones, cabrones, muera el SEU, matones asesinos de febre$\mathrm{ro}^{21}$. El relator de este informe apuntaba: "Al ocupar el estrado el camarada Illueca, Inspector Nacional del SEU, que ostentaba la representación del Jefe Nacional, el alboroto adquirió tal proporción, que el Magnífico Rector de la

\footnotetext{
y de construcción en barriadas como Conxo, 0 Castiñeiriño o A Choupana. Entre las personas destacadas que pasaron por el SUT gallego podríamos destacar a Carlos París, Juan Anlló, Juan Wulff, José María Calviño, Carlos de Blas, Francisco Díaz-Fierros o Ezequiel Méndez.

${ }^{21}$ Datos tomados de "Relación detallada de los sucesos ocurridos en los últimos días de la III Gran Semana Universitaria Compostelana”, firmada el 12 de julio de 1954. Agradecemos a Elena Hernández Sandoica y a Miguel Ángel Ruiz Carnicer su cesión (Archivo MEC, sig. 26.021).
} 
Universidad, que presidía el acto, ordenó la suspensión del mismo, que fue hecha pública por el Jefe del SEU". Los estudiantes salieron en manifestación a la contigua plaza de la Universidad; desde allí contemplaron como otros compañeros "ahorcaban" en el mástil de la bandera del edificio un muñeco de papel que representaba al jefe del SEU. Según el informe, aparecieron pintadas alusivas a la FUE y algunos alumnos levantaron el puño "repetidas veces"; incluso, siguiendo el relato, no exento de épica inculpatoria, decía que hubo octavillas en las facultades los días posteriores con "escritos subversivos". Alguno de ellos con la sigla ALU (Asamblea Libre Universitaria), tal y como los estudiantes venían reivindicando en otros distritos. En la tarde de autos, se escucharon voces de "abajo el SEU" que interrumpieron el comienzo del recital del Orfeó Catalá, con una cierta complicidad de los cantores catalanes.

Uno de los alumnos participantes en los altercados, Juan José Fernández Teijeiro, que luego fue expedientado, informaba de la presencia policial en la puerta para impedir la entrada al Paraninfo y la voz del catedrático Carlos de Miguel dirigiéndose a los alumnos: "En la calle lo que queráis, pero en nuestra casa no"22. Este alumno relataba en la misma grabación: "Éramos muchos y de todas las facultades. Luego fuimos al bar del SEU, gritando "todo gratis". Recuerdo que uno de los encargados exclamó: "Estos son peores que los del 36"; forzamos para poder entrar al local y nos fue impedido desde dentro. En el forcejeo rompieron los cristales". En definitiva, el altercado se saldó con cuatro expedientes disciplinarios -dos de ellos eran hijos de militarescanalizados por dos vías: sindical (SEU) y académica. El primero se cerró con amenaza de expulsión del sindicato universitario de los cuatro encausados, después de que realizasen un pliego de descargos a la Secretaría General del Movimiento, y el segundo con un traslado de la voz del ministro de Educación por boca del rector, según Fernández Teijeiro: "Me ha dicho el Ministro que no vuelvan a hacer esto, que sean buenos. No vuelvan a hacer estas cosas, hombre...." El paternalismo de Legaz llegaba a esto y la tolerancia de RuizGiménez, se le suponía.

Era la primera vez que la protesta universitaria ocupaba las calles de Compostela y el edificio central de la Universidad como reacción masiva contra las autoridades; y que el fervor anti SEU se escuchaba de viva voz. Aunque no podamos calificar lo acontecido como expresión política propia, la rebel-

${ }^{22}$ En grabación realizada a Juan José Fernández Teijeiro, en Santander, en 15 de setiembre de 2008, depositada en la Fundación 10 de Marzo de Santiago de Compostela (como todas las que se citan después). 
día potencial de emancipación de los mozos compostelanos pudo tener algún avivado motivador, o varios, que vislumbraron la posibilidad de que "hubiese condiciones objetivas" para desencadenar el altercado anti jerárquico con gran apoyo. Más aún si aquel año 1954 era Santo Jubileo. Diez años largos pasaron antes de volver a ver algo semejante en la USC. No descartamos que la organización de la "asonada" partiera de los colegios mayores, donde vivía el quince por ciento del estudiantado de Compostela. Y, seguramente, su "espontaneidad" viniese por iniciativa de algunos significados líderes de los movimientos católicos.

El Galleguismo despierta con la cultura y los estudiantes católicos se aproximan a la realidad social y al compromiso

Una parte de los discípulos aventajados de Piñeiro que habían triunfado en los concursos poéticos del SEU, junto con otros estudiantes gallegos de la Universidad Central, dieron un importante primer paso asociativo al crear la plataforma cultural Brais Pinto (1958) en Madrid. Interesados en la creación artística y las vanguardias, con la renovación de la cultura gallega en el horizonte, estos mozos, no exentos de cierto elitismo, pusieron a andar esta iniciativa que, con el tiempo, se fue convirtiendo en espacio de reflexión política y germen de propuestas nacionalistas. De sus fundadores destacamos al escritor Xosé Luís Méndez Ferrín. Brais Pinto cuenta entre sus logros la creación de una editorial. En 1960, fue en Barcelona donde estudiantes gallegos, en contacto con Ramón Piñeiro, pusieron en marcha la Mocedade Galega, de la mano de uno de los agentes culturales más importantes que tuvo nuestro país, Manuel Caamaño. En este caso realizaron, fundamentalmente, actividades de autoformación en materias relacionadas con Galicia y su lengua. En ambos casos aprovecharon espacios comunes, como eran los centros gallegos, y contaron con el apoyo y amparo de viejos galleguistas.

Mientras, en Compostela echa a andar en 1961 la asociación cultural O Galo, por iniciativa de estudiantes y creadores artísticos, también de la escuela de Piñeiro. Con un carácter más abierto y de intervención pública, esta asociación tuvo un importante impacto entre el estudiantado universitario de la época, que se mantuvo hasta el final de la Dictadura, después de soltar amarras con su impulsor por discrepancias y los miedos de este "a lo político". Su labor, en un primer grado de sensibilización, consistió en la propagación de la lengua y la cultura propias entre el estudiantado: formación, 
creación y difusión cultural. Simiente de propuestas políticas galleguistas/ nacionalistas de diferente factura ${ }^{23}$.

Mientras el distanciamiento con el SEU se patentizaba al paso de los días, este organismo se limitaba a labores burocráticas y asistenciales. Su debilidad manifiesta la hacía permeable a la "penetración" de los estudiantes más inquietos, para intervenir desde dentro de las estructuras de representación en las cinco facultades que había, con buenos resultados. Tanto el galleguismo como los grupos cristianos organizados, en su condición de no sospechosos, en principio, fueron copando puestos con el propósito de actuar sin condicionantes políticos de "adicción". Comenzaban a trasladarse inquietudes democráticas, con cierto compromiso de intervención.

Los estudiantes católicos también se habían distanciado de su jerarquía, connivente con el Régimen, motivados en buena medida por las expectativas del Concilio Vaticano II. La aproximación a la realidad inmediata mediante análisis personal y colectivo -revisión de vida: ver, juzgar y actuar-y la crítica a las iniquidades de la Dictadura eran sus banderas para propiciar su praxis vital, empujados por unos consiliarios que reprobaban las estructuras nacionalcatólicas y sus procedimientos de "adhesión".

Uno de los delegados que intervenía con sentido cristiano, Francisco Díaz-Fierros, añadía: “El tema confesional, que, por supuesto, todos lo vivíamos, no era lo fundamental, sino el carácter del estudiante como trabajador y como representante comprometido" 24 . En el caso de las ramas organizadas del catolicismo, aunque unos años más tarde, en Santiago acontecía lo que había sucedido en el resto de los distritos universitarios. Como elementos diferenciales de la disidencia estudiantil apuntamos la ausencia en Compostela del FELIPE en toda la década y la tardía aparición de la militancia comunista en la USC, que va a emerger con Machado de pretexto, en 1964, y con el Mundo Obrero circulando ya por las facultades.

En aquel primer trienio de los años sesenta hay acontecimientos que, de alguna forma, marcarán la intervención estudiantil en todo el Estado español: los sucesos de Asturias y su estado de excepción, más el “contubernio de Múnich", con la consabida represión posterior contestada solidariamente por sectores intelectuales y universitarios. En el ámbito publicístico, la apa-

${ }^{23}$ Ricardo Gurriarán, “El movimiento estudiantil en la Universidad Gallega. De la calma a la subversión”. En Galicia en Transición, dirigido por Julio Prada (Madrid, Silex, 2019): 225-227. Queremos significar la aparición del Partido Socialista Galego (PSG, 1963) y la Unión do Pobo Galego (UPG, 1964), ambas de largo recorrido, y de ida y vuelta. Aunque tuvo poco impacto, el galleguismo político intentó una alternativa democristiana que no fructificó.

${ }^{24}$ En entrevista efectuada a Francisco Díaz-Fierros, en Santiago, el 21 de junio de 2007. 
rición de Triunfo (1962) y Cuadernos para el diálogo (1963) resultó clave en la agregación de adeptos al antifranquismo, fundamentalmente entre la mocedad universitaria. Su lectura fue el complemento crítico a la labor militante que llevaban a cabo las organizaciones políticas clandestinas, sobre todo del Partido Comunista. Aunque los editores de estas publicaciones lucharon contra los nuevos márgenes de la censura post scriptum, con trampa impuesta por Fraga y su Ley de Prensa, su itinerario fue largo, fructífero y de hondo calado, a pesar de multas y secuestros. Fraga, desde su ministerio, también controlaba la acción cultural y su supervisión, e interviene en la "extinción del incendio" de los mineros asturianos.

No podemos olvidar el papel que jugaron los textos del Concilio Vaticano II, que van a ser el desencadenante definitivo de la ruptura entre base y cúpula de la Iglesia. La encíclica Mater et Magistra (1962), entre otros textos de aquel concilio, daba las claves sociopolíticas para empujar hacia la conquista de valores democráticos y derechos fundamentales. De este modo, la juventud católica -ramas juveniles y obreras: JOC, JEC y HOAC- tomaba un nuevo rumbo de intervención, con voz propia, y demandaba libertades y apertura, bien apoyada por sus publicaciones Signo y Eclessia; en Galicia, con una especificidad añadida: la reivindicación de la lengua del pueblo gallego en la liturgia. De esta forma surge la Mocedade Galega Universitaria Católica, alrededor de 1963, casi de preocupación lingüística exclusiva, con el apoyo de Ramón Piñeiro.

Esta década había comenzado con un cambio de rector. El incombustible Legaz Lacambra, después de dieciocho años de mandato, dejaba el puesto al catedrático de Anatomía Ángel Jorge Echeverry, que tendrá especial protagonismo en 1968. Legaz, después de solicitar el traslado a Madrid, enseguida se incorpora al equipo ministerial de Lora Tamayo en Educación. Entre planes de desarrollo, terceras vías políticas, con el Opus Dei mandando en los ministerios económicos, tiene lugar en Santiago una intervención desenfadada de los mozos galleguistas durante el acto de entrega de los premios de las Fiestas Minervales de 1963. Los tres premiados en la modalidad de poesía en gallego criticaron en sus intervenciones, ante autoridades docentes, civiles y militares, el desgajamiento territorial de las provincias de Lugo y Ourense en el I Plan de Desarrollo para Galicia, adscribiéndolas al Polo Industrial de Valladolid: una reacción reivindicativa frente a la pretendida ofensa territorial; un yo protesto en nombre de los estudiantes. Al igual que lo haría, de forma metafórica, el mantenedor del acto, el patriarca Otero Pedrayo, quien aludió a los impulsos de libertad de los estudiantes. Una campaña posterior contra aquella imposición hizo que las autoridades políticas desistiesen de su pretensión. 
A este indicador de que las cosas estaban cambiando se unía otra iniciativa de claro contenido político, con riesgo y repercusión pública: un mes antes, los estudiantes reaccionaban en la calle y se rebelaban ante las consecuencias de una protesta vecinal contra la repoblación forestal cerca de Santiago, que se había saldado con un muerto a tiros por la Guardia Civil y trece detenidos. Los alumnos de Derecho más concienciados difundieron por las aulas lo ocurrido y organizaron una movilización espontánea solidaria y de rechazo. Llamaron a concentrarse en la Alameda contra aquel suceso. Ante la abundante presencia policial, no pudieron agruparse en este lugar. Después de trasladarse a la vecina praza do Toural, el estudiante Alfonso Paz-Andrade se dirigió a sus compañeros concentrados para denunciar públicamente al Régimen. Estamos ante la que podríamos calificar de primera movilización política estudiantil en Santiago (1963). El distrito se incorporaba a la lucha estudiantil antifranquista. La cultura como herramienta de agitación pasaba a ocupar sitio preeminente, y la masa crítica entre el alumnado crecía.

Pero también algo empezaba a cambiar en una institución que no podía mantenerse al margen de un escenario incómodo y cerrado. La mínima presencia de catedráticos "de antes de la guerra" propició que parte del nuevo profesorado fuese abandonando la discreción y el silencio: pronto saldrían del mutismo. Desde el seno del equipo universitario comenzaron a activarse propuestas culturales "sin excesiva connotación de adhesión", coexistiendo con las actividades de un SEU moribundo: homenajes a liberales como Marañón, a los proscritos profesores de la USC Nóvoa Santos y al rector republicano Cadarso, o a Valle Inclán; o la voz de conferenciantes como Severo Ochoa y Santiago Montero Díaz. También empezaba una tímida y progresiva colaboración de profesores en actividades organizadas por el alumnado: charlas, seminarios, revistas orales, aulas de poesía, publicaciones... Y en la presentación y en los debates de las sesiones del cineclub, que iniciaba su andadura en 1961 bajo el amparo del SEU, pero que no tardaría en despojarse de tales siglas, adquiriendo su independencia en 1965, bajo la conducción de su presidente Ezequiel Méndez, un importante activo en el fomento del análisis crítico entre el estudiantado, a modo de escuela democrática.

Lucas Verdú, profesor encargado de la Extensión Universitaria, organizaba ciclos de conferencias para hacer visibles temáticas de actualidad como el europeísmo, los sistemas universitarios en países democráticos o la novedosa encíclica Mater et Magistra. Y el vicerrector Carlos de Miguel osaba reflexionar sobre la necesidad de diálogo entre docentes y discentes en el 
periódico local ${ }^{25}$. Entre el alumnado cobraba relevancia la proliferación de grupos de teatro. Autores críticos como Buero Vallejo, Sastre, Brecht, O’Neill, Camus... copan los escenarios. La Antígona de Anouilh es traducida al gallego. Y la emblemática obra de Castelao Os vellos non deben de namorarse se estrena en el marco de la praza da Quintana (1961) con el citado Ezequiel Méndez entre sus principales actores.

La Facultad de Filosofía y Letras toma la delantera en actividad cultural y militancia política. En este espacio, el "humus" antifranquista prende y se expande con cierta visibilidad de la mano del "comunista oficial" Luís Cochón, quien fue capaz de agrupar un importante núcleo de simpatizantes para iniciarlos en su formación de agentes agitadores o, simplemente, como activos colaboradores de sus acciones. Quiero apuntar que, en cuanto a las características del militante universitario, en cualquier grado, bien comunistas o nacionalistas, el compromiso venía más por afinidad de espacios comunes con los líderes, porque procedían del mismo lugar, o por la convivencia diaria, que por razones ideológicas o partidistas. Además, la débil e incipiente estructura de los partidos, o, incluso, enfados personales, pataletas o excesos de celo, facilitaban la transferencia de adscripción de un partido a otro. A nuestro entender, con carácter general, no se puede hablar sensu estricto de militancia partidista. Más bien de sintonía rebelde y hartazgo de ver iniquidades en redor. A este particular, el delegado Ezequiel Méndez apuntaba su visión de aquella época como "compañero de viaje del PCE":

Los subterráneos estaban más poblados de lo que uno alcanzaba a percibir. Sólo así se explica lo que más tarde sucedería. Al no poseer estatus de militante en ninguna organización no estoy en condiciones de profundizar sobre el particular [...] Políticamente, todo era muy embrionario. La clandestinidad enviaba panfletos ciclostilados y empezábamos a intuir el grado de compromiso de cada cual ${ }^{26}$.

En la Facultad de Letras se hicieron ciclos de poesía social con textos de Hierro, Celaya, Blas de Otero y Miguel Hernández, con gran repercusión entre el alumnado. Se conmemoró el centenario de Cantares Gallegos de Rosalía de Castro (1963), con carácter oficial y no exento de enfrentamientos con el SEU. Se cantó el himno gallego por vez primera desde 1936. Se homenajeó a Machado con un acto donde conferenció Montero Díaz (1964); presentó Cochón, que fue rescatado de la comisaría de policía por el propio Montero. Un acto que el estudiante de Letras y simpatizante comunista Ra-

${ }^{25}$ Gurriarán, "El movimiento estudiantil": 232.

${ }^{26}$ En cuestionario respondido por Ezequiel Méndez, en marzo de 2007. 
fael Chacón caracterizaba así: "Los alumnos y alumnas presentes vieron que existía disidencia y gente comprometida que se atrevía a decir cosas hasta aquel momento nunca escuchadas en Compostela"27.

Los estudiantes comunistas comenzaban a hacerse visibles y a disputar los espacios culturales al galleguismo. Con su metodología activa y sus contenidos más ideologizados, pronto alcanzaron un buen número de adeptos. Se empezaba a perder el miedo. No pasaría mucho tiempo hasta que estudiantes comunistas y galleguistas/nacionalistas comenzasen a colaborar y llevar a cabo acciones conjuntas. Antes, la organización estudiantil del PC, junto a la agrupación local del partido, conmemoraron en la calle el primero de mayo de 1965.

1965: Madrid se levanta, cae el SEU y Franco es nombrado Honoris Causa bajo el cielo de Compostela

Los sindicatos libres empiezan a ser un clamor en los distritos universitarios, desde comienzos del año 1965. La suspensión de actos culturales en el mes de febrero por las autoridades académicas genera respuestas en demanda de democracia y libertad en el campus madrileño, a las que se agregan algunos profesores. Se convoca una asamblea con miles de estudiantes donde se confecciona un documento en el que se reclaman libertades, reforma universitaria y solidaridad con las reivindicaciones obreras. Al pretender entregarlo en el Rectorado, una carga policial impide que se aproxime la marcha de alumnos y profesores. Heridos y detenciones, sanciones y expedientes. Solidaridad en los distritos, al tiempo que el SEU da los últimos pasos como corporación. Ante la situación, las autoridades políticas sacan un decreto de apariencia democrática (abril de 1965) con el que cambian el nombre al sindicato estudiantil único por Asociaciones Profesionales de Estudiantes, manteniendo prácticamente el sistema electivo anterior. El rechazo es unánime en los distritos y se prepara un Congreso Nacional de Estudiantes. La petición del levantamiento de las sanciones se extiende enseguida como reivindicación inmediata.

Aquel Año Santo, Franco paseó bajo palio por las rúas compostelanas. Pocos días después de nombrarlo doctor honoris causa en la Facultad de Ciencias de Santiago, en A Coruña, corriendo agosto, se celebra un Consejo de Ministros donde se materializan las sanciones al profesorado que había

\footnotetext{
${ }^{27}$ En entrevista grabada en Ponte Bora (Pontevedra), en 20 de abril de 2007.
} 
participado en los sucesos de febrero, con la expulsión a perpetuidad de tres catedráticos y la suspensión de empleo y sueldo de otros dos. Ya en setiembre, la cadena solidaria se extiende a Compostela y, por vez primera, un colectivo profesional en Galicia, en este caso algunos catedráticos de la USC, se agregaba a la demanda del levantamiento de sanciones mediante un escrito de adhesión dirigido al Ministro de Educación: "Para que queden sin efecto las sanciones impuestas a los compañeros don José Luis López Aranguren, don Enrique Tierno Galván, don Agustín García Calvo, don Santiago Montero Díaz y don Mariano Aguilar Navarro"28.

Pero antes de los acontecimientos estivales en Compostela, la estela solidaria ante los sucesos de febrero destapó la necesidad de organizarse unitariamente en la efímera plataforma ALEU (Asamblea Libre de Estudiantes Universitarios), con la idea de federarse con organizaciones de otros distritos. La libre sindicación, el derecho a huelga y las libertades políticas formaban parte de sus reivindicaciones democráticas. Comunistas, en solitario en un principio, luego cristianos e independientes bajo las siglas ADE (Agrupación Democrática de Estudiantes, 1965) y algún galleguista más todos los estudiantes con perfil de bajo compromiso que se vieron reforzados por los sucesos de Madrid, ante la necesidad de dar una respuesta, potenciaron esta iniciativa algo imprecisa. Lo que sí quedaba claro era la necesidad organizativa frente a las iniquidades del Régimen y la coordinación territorial. Después de distribuir una serie de cinco panfletos con una convocatoria de asamblea, esta se celebró el 26 de marzo ante más de doscientos estudiantes, según la policía ${ }^{29}$. Allí se propuso una próxima huelga si no se levantaban las sanciones y expedientes de Madrid, y la necesidad de convocar juntas de facultad para votar la ruptura con el SEU. Esta propuesta tuvo eco, no sin acarrear problemas con las autoridades académicas y el seuismo más recalcitrante. Las hojas informativas y los boletines comenzaban a circular con normalidad por las aulas.

La información de lo que iba aconteciendo en otros distritos pronto llegaba a Santiago. Las propuestas de representatividad se discutían. El

${ }^{28}$ Estaba firmado por los conocidos profesores de actitud liberal que había en la USC: Ramón Domínguez Sánchez, Adolfo Núñez Puertas, ambos de la Facultad de Medicina; Enrique Vidal Abascal, de Ciencias; Enrique Moreno Báez y Fernando Montero Moliner (catedrático de Fundamentos de Filosofía, tan sólo estuvo en Santiago dos cursos, desde 1964), de Filosofía y Letras; a los que se agregaron Gumersindo Fontán Maquieira y Benito Regueiro Varela, de Medicina, más Rafael Cadórniga Carro, de Farmacia, y Ramón Otero Túñez de Filosofía y Letras. Agradecemos al profesor Fernando Domínguez la cesión de este importante documento inédito.

${ }^{29}$ Copia de documentos policiales depositados en la Fundación 10 de Marzo (Fondo Goberno Civil, A Coruña), procedentes del Arquivo Histórico de Galicia (A Coruña). 
decreto del 5 de abril abría algo el marco electivo de los delegados. Ante las posibilidades que se formulaban, pronto se apostó por el posibilismo de aprovechar las nuevas estructuras para derrotar al neoseuísmo que trataba de enmascararse como neodemócrata. De nuevo la voz de Ezequiel Méndez es clara al respecto de la no colaboración con el SEU, "una decisión ética por obligación moral":

Durante el curso 1964/65 se acrecentaron las contradicciones que desembocarían en nuestra renuncia a seguir colaborando con las actividades del SEU. La vida estudiantil era cada día más inquieta. Se estaba gestando lo que había de ser una oposición frontal a la existencia del Sindicato Universitario. El boicot a las elecciones de delegados de curso y de facultad gestionadas por el SEU y la aparición de un incipiente y clandestino movimiento asociativo democrático, así como la organización de actividades culturales fuera del ámbito del sindicato franquista, nos situaban ante la necesidad de reaccionar coherentemente. No era posible luchar contra el SEU en las aulas y espacios universitarios y, al mismo tiempo, mantener nuestra colaboración en "su" cineclub y en "sus actividades culturales" 30 .

De esta forma, el Cineclub del SEU dejó de serlo y pasó a asociarse con la Agrupación Fotográfica Compostelana, con Ezequiel en la dirección de la nueva entidad. Al comenzar el curso siguiente, las declaraciones de separación de las estructuras seuístas por parte de las juntas de facultad y las dimisiones de los viejos delegados avivaron los procesos electivos nuevos, aunque algunos "enfeudados" quisieron seguir siendo del SEU. La alianza táctica entre la militancia comunista y el grupo ADE, manteniendo sus singularidades, comenzaba a dar frutos en algunas acciones. El germen unitario estaba en marcha y la toma de iniciativas era un hecho, no exento de problemas, en un escenario adverso. El profesorado adicto que ocupaba cargos académicos trataba de frenar el despertar organizativo, al tiempo que el Ministerio prohibía la celebración de asambleas. También la policía empezaba a controlar al estudiantado más activo. Sobre aquel momento y la percepción del humus antifranquista que se iba consolidando en Compostela, el activo José María Calviño comentaba: "Pasada esta primera etapa, las etapas siguientes, que yo llamaría de consolidación, fueron el resultado de una colaboración interpersonal transparente, de absoluta confianza, de una serie de gente que era el fermento y la dinamización, aunque no militamos nunca" ${ }^{\prime 31}$. Se había perdido

${ }^{30}$ Ezequiel Méndez Vidal, "Memoria contextualizada de mi actividad teatral", mecanoescrito personal inédito, 81. El nuevo cineclub comenzó a andar el 7 de noviembre de 1965 con Eva de J. Losey (1962).

${ }^{31}$ En entrevista grabada en Madrid, 23 de marzo 2007. 
el miedo entre los líderes estudiantiles y allegados y se vislumbraba una agregación de activos a la lucha, a corto plazo, con adquisición de compromiso social y político, más allá de sus reivindicaciones corporativas. Salir a la superficie y la actitud unitaria les habían dado buenos resultados, con la ayuda de la agitación transversal mediante la cultura.

En el ámbito docente, la renovación era la pauta en esta segunda mitad de la década, pero de ida y vuelta, pues la mayoría de los nuevos profesores no duraban aquí más de tres cursos. Es el caso de Montero Moliner, Monge Casao o González Casanova, de espíritu abierto y métodos docentes avanzados. Este último, militante antifranquista en Cataluña, colaboró en actividades estudiantiles de aroma democrático. También es significativa la llegada a Santiago de Vicente Álvarez Areces en octubre de 1966, experto militante comunista, quien imprimirá impulso y pragmatismo al movimiento estudiantil. En aquel curso, ADE copó la mayoría de los delegados elegidos democráticamente, el Consejo y el presidente de distrito, bajo la nueva normativa de las Asociaciones de Estudiantes, con el SEU liquidado y con sus residuos derrotados. Tan sólo se habían constituido dos sindicatos democráticos, al margen de la legalidad, en Madrid y Barcelona. En Santiago, el triunfo en las elecciones supuso una importante dotación de medios a los representantes y un ascenso de la masa crítica que pronto iba a adquirir protagonismo. Areces analizaba así la situación: "En aquel momento, el sentido de adversario no existía. Había un sentimiento muy unitario que era lo que hacía la argamasa para que todos estuviésemos identificados: luchar contra la dictadura y por las libertades. Lo fundamental era esa arquitectura que íbamos construyendo a través de un dispositivo sindical, transgrediendo la norma oficial que había en el momento, pero sin aislarnos de los propios estudiantes"32.

En el bienio 1967-1968 se dio un importante avance en el ámbito cultural comprometido, con profusión de actos organizados por el estudiantado. La conferencia de José Luis L. Aranguren en el Burgo de las Naciones, finalizando enero, acabó tras la suspensión policial del acto cuando iba a comenzar el coloquio, por carecer de permiso gubernativo. Luego fueron detenidos el presentador, Carlos Casares, y el conferenciante, en presencia de quinientas personas ${ }^{33}$. Tras una concentración de estudiantes delante de la comisaría, Aranguren salió después de declarar y Casares al cabo de unas horas. En marzo se presenta la ópera prima de Carlos Casares, Vento ferido,

\footnotetext{
${ }^{32}$ En entrevista grabada en Oviedo, 24 de septiembre de 2007.

${ }^{33}$ Había sido convencido por estudiantes en casa de García Sabell, a quien venía a visitar. Iba a hablar sobre el futuro de la universidad.
} 
referencia de la nueva narrativa gallega, en la Facultad de Ciencias ante un abarrote de estudiantes. Ese mismo mes, como ya se había hecho en otros distritos, se celebró una Semana de Renovación con Eduardo Cierco, el economista García Delgado y los profesores José Rodríguez y Manuel Sacristán, aunque este último, detenido en esos días, no pudo intervenir. También pasaron a disertar otros "agitadores", como el canónigo González Ruiz, Jesús Aguirre o gente del grupo de Cuadernos para el diálogo, entre otros.

Al tiempo, los estudiantes reaccionaban frente a los actos oficiales que organizaban las autoridades. Sus furias se desataron boicoteando intervenciones y charlas de destacados hombres del Régimen como Blas Piñar, que venía de mantenedor de las últimas Fiestas Minervales (1967); o el ministro López Bravo y el cuñado de Fraga, Robles Piquer. Las acciones de los estudiantes se empezaban a hacer visibles en actos públicos y la prensa recogía su "protagonismo". El miedo a la transgresión y sus consecuencias represivas ya poco contaban. El cambio de vivir de patrona o de pensión al de agruparse en pisos de estudiantes fue un paso cualitativo importante para organizarse mejor y para ganar adeptos, además de servir de "depósito" y de producción propia de material variado. Los mozos y mozas cristianos organizados en ADE acudían a unas tertulias de debate que reforzaron el paso del compromiso individual al de la crítica a la realidad circundante y a dar soluciones de cambio.

Pero el acto más importante de aquel 1967 fue el recital del cantautor valenciano Raimon en el estadio de la Residencia Universitaria. Aquel 9 de mayo dejó una huella difícil de borrar en los tres mil universitarios y universitarias que acudieron al concierto. Cantar en lengua propia como lo hizo el setabense, en un escenario rodeado de pancartas en gallego y con la traducción de sus canciones al idioma del país recogidas en un libretillo, infundió al estudiantado un soplo de identidad y de autoafirmación superlativo. Se puede decir que el ambiente antifranquista, a pesar de la gran presencia policial, fue la nota dominante y el principal fuelle para seguir adelante en la lucha.

La coordinación con el resto de distritos era una realidad desde la reunión de coordinación preparatoria de Valencia a principios de febrero de 1967. No habían funcionado las claves de clandestinidad necesarias y, después de acordonar el edificio, la policía practicó una detención masiva; entre los apresados se encontraba el delegado de Filosofía y Letras de Santiago, Mauro Fernández. Enseguida se convocó la primera huelga universitaria en Compostela, en una asamblea de más de dos mil estudiantes, que confluía con un fuerte clima de agitación laboral en Galicia por los despidos de Bazán.

Culminaba un período de movilizaciones solidarias con otros distritos. Los encierros y manifestaciones empezaban a entrar en el día a día de los 
estudiantes. Y los desencuentros con profesores que no reconocían a los delegados electos comenzaban a airearse en los boletines de facultad.

\section{Las condiciones objetivas que vienen: "el 68"}

Ya estaba en marcha el movimiento democrático estudiantil contra la dictadura de Franco, también en Compostela, mientras en otras latitudes la juventud rebelde soltaba amarras y reivindicaba presencia sin tutelajes ni autoritarismos. Los líderes santiagueses leyeron muy bien escenarios, actores, pretextos y consecuencias. Y aplicaron correctamente el binomio acciónnegociación, con sentido de anticipación cuando las condiciones lo permitían. Con una buena administración de recursos y una gestión óptima de la situación en cada momento -análisis previo y respuestas reactivas, sin perder nunca la iniciativa-, los resultados no se hicieron esperar. Estas acciones desconcertaban y dejaban instantáneamente sin recursos a las autoridades políticas y académicas, que cometían torpezas constantes. A mayores de que los representantes estudiantiles jamás se habían negado a la negociación para la solución del conflicto, más bien al contrario.

Aparte de tener en cuenta, como elemento clave, la organización y distribución de la información en dos direcciones, la organización estudiantil realizó una labor de manual para extender el conflicto y sus reivindicaciones más allá de las aulas. No solo informaron de forma impecable hacia adentro, con boletines que comunicaban cada avance, y concertando puntualmente la toma de decisiones en asambleas, sino que fueron capaces de llegar a la sociedad local y al resto del país, que respondieron con sobradas muestras solidarias, incluso públicas. Para esta labor contaron con parte de la prensa que empezaba a dar cobertura y difundir con connivencia democrática las injusticias que se estaban cometiendo en las aulas compostelanas; fundamentalmente, diarios que habían sufrido sanciones económicas importantes, como La Voz de Galicia. En definitiva: inteligencia política, capacidad organizativa y eficacia comunicativa.

La conexión entre los diferentes núcleos de representación inter y extrafacultades funcionaba sin tacha, lo mismo que los departamentos estudiantiles. La producción de boletines era prolífica. Y las acciones solidarias contra la represión policial en otros campus fue una constante hasta la focalización del conflicto en Compostela. Aquí, podríamos decir que, tras una fase de consolidación y avance democrático, comenzó el curso con homenajes al Che Guevara, sin permiso oficial, y con problemas de locales para actos culturales y de reunión. Los alumnos desafiaban la legalidad ampliando el 
número de delegados elegibles y las autoridades académicas no reparaban a la hora de suspender actos. Después de las Navidades comienzan movilizaciones solidarias con los distritos y una huelga, con gran respuesta en Ciencias. En una manifestación se realiza una quema de periódicos que se salda con diez detenidos, de los que seis llegan al TOP. Concentración delante de la comisaría pidiendo libertad para los detenidos. En tanto, el decano de Ciencias, Joaquín Ocón, en un rebato autoritario, busca confrontación y declara ilegales los boletines informativos y cuelga un listado de los principales instigadores de la huelga. El delegado Areces es detenido e ingresa en la cárcel provincial, tras negarse a pagar una multa gubernativa. Tras una negociación con el rector Echeverri, este se ofrece para mediar con el gobernador y Areces sale antes de cumplir los veinte días sustitutivos. Entretanto, los boletines airean la conmemoración del XX aniversario de la Declaración Universal de los Derechos Humanos.

"Se quedan con nuestro dinero", rezaba el titular del boletín de Ciencias no 11 (23 de febrero de 1968), haciendo referencia a las cuotas de matrícula que debían revertir en las organizaciones estudiantiles de Ciencias para actividades. Por este motivo se convoca-sin permiso- una asamblea el 6 de marzo, donde se decide ir a la huelga. Ante quinientos estudiantes, el decano Ocón irrumpe para llevarse con él al delegado de facultad a la comisaría, al tiempo que expulsa de la facultad a algunos delegados que estaban en la mesa. Y se armó, pues estas fueron las consecuencias: la convocatoria por la Cámara de Cámaras (máximo organismo de representación, llamado familiarmente "camarón") de una huelga solidaria con Ciencias en toda la USC y una marcha pacífica hasta el rectorado, donde se celebraba una Junta de Gobierno. Al no poder entrar por la presencia policial, los estudiantes deciden posteriormente encerrarse en el rectorado hasta que sus peticiones sean atendidas, en una actitud claramente negociadora. La dimisión de Ocón flotaba en el aire. En nombre del rector, tres profesores "buenos" ofrecen unas vacaciones del Decano y la devolución de las cuotas si dejan el encierro; los alumnos no aceptan la oferta y permanecen en el recinto ${ }^{34}$. Tres días después son desalojados pacíficamente por la policía, luego de mediar el rector con el gobernador civil.

Primer triunfo: negociar en pleno franquismo, bajo presión; obtener gestos de solidaridad del vecindario y lograr una repercusión pública del conflicto. Además de conseguir un éxito mediático, con cierta complicidad democrática del cuerpo periodístico, que desembocó en un llamamiento ge-

${ }^{34}$ Durante el encierro se celebró una conferencia de Armando López Salinas sobre los derechos humanos, correspondiente a la Segunda Semana de Renovación. 
neralizado al diálogo. En una magna asamblea de tres mil estudiantes, se decidió mantener la huelga. La oleada represiva contra los alumnos más significados marcó el calendario. Llega el juez del TOP Mariscal de Gante para materializar las sanciones a los delegados de Ciencias. Más detenciones y expedientes disciplinarios alimentan la continuidad de la huelga. La demanda de negociación se patentiza para buscar soluciones al conflicto. Se logra obtener el reconocimiento de una comisión de veinte representantes ante el gobernador civil, estando en huelga.

Tras casi un mes en huelga, llega a Santiago el director general de Universidades, Hernández Díaz, para sancionar a los principales "agitadores". El estudiantado recibió al político con una gran asamblea en Medicina, fuertemente reprimida por la policía; también la despedida en la Estación, donde los adoquines volaron en Santiago antes que en París, aquel 28 de marzo de 1968. Heridos, detenciones, multas y cárcel para estudiantes, después de estos enfrentamientos. Desde el profesorado comienzan a mostrarse signos de rechazo a las sanciones y a la violencia, a los que se suman corporaciones profesionales, sindicatos clandestinos, clero en sus homilías, incluso el cardenal Quiroga hace una llamada a la conciliación.

Poco antes dimitía el ministro de Educación, no sin antes conceder al decano de Ciencias una licencia para dedicarse a la investigación. El equipo de gobierno adelantó oficialmente las vacaciones de Semana Santa, con carácter disuasorio. Son liberados los detenidos y los estudiantes deciden en asamblea dar un plazo de diez días para que sus reivindicaciones se satisfagan, en un clima de movilizaciones en todos los distritos. Se anuncia un referéndum para el 2 de mayo con el fin de tomar decisiones. Con una participación de las tres cuartas partes del alumnado, el resultado es favorable a continuar en huelga ( $54 \%$ ). Conocido este resultado, el rector, con afán desmovilizador, anuncia el mismo día la devolución de las cuotas de matrícula y la suspensión de sanciones. Los estudiantes habían ganado, a mayores de que el decano Ocón había sido desplazado a La Laguna y Hernández Díaz cesado; luego vendrían los ceses del gobernador civil Avendaño Porrúa y el rector Echeverri.

Aquel conflicto fue uno de los más destacados aquel año en España. Aun con el resultado de trece expedientados y algunos procesos judiciales prolongados en el tiempo, su respuesta organizada fue un ejemplo de manual. Una lucha poco conocida por la historia oficial, con amarga victoria pero, al fin, victoria. Aquel 2 de mayo, cuando los estudiantes franceses comenzaban sus manifestaciones, los compostelanos retornaban a las aulas con un triunfo moral y efectivo. 
Buena parte de los estudiantes que participaron en esta lucha formaron, con el tiempo, los mimbres del tejido político de la Transición. Hemos visto como desde el silencio y la "sumisión obligada", aunque con tardanza, se pasó a clamar libertades y democracia, perdiendo el miedo. Como nos dijo en su día el sociólogo Fermín Bouza, activo antifranquista en aquel entonces: "El 68 en Compostela fue un momento clave para propagar todo lo que luego había de ser la modernización política de Galicia"35. Algunos no llegaron y, tras un estado de excepción duro en 1969, se fue haciendo camino hasta la muerte del dictador. Lo duro ya estaba hecho. Su participación en la conquista de las libertades democráticas, también ${ }^{36}$.

\section{Bibliografía}

Alonso Zamora, Vicente. Compostela, años atrás. Santiago de Compostela: Servizo de Publicacións da USC y Consorcio de Santiago, 1993.

Franco Grande, Xosé Luís. Os anos escuros. Vigo: Edicións Xerais, 1985, tomo I.

Grandío Seoane, Emilio. "Dereita e rexionalismo galego na II República: Carlos Ruíz del Castillo", Grial 35, 134 (abril-junio 1997): 185-217.

GURRIARÁN, RICARDo. Ciencia e conciencia na Universidade de Santiago (19001940). Do influxo institucionista e a JAE á depuración do profesorado. Santiago de Compostela: Servizo de Publicacións da USC, 2006.

Gurriarán, Ricardo. Do "Gaudeamus igitur" ao "Venceremos nós". As mobilizacións estudantís do 68 en Compostela. Santiago de Compostela: Fundación 10 de Marzo, 2008.

Gurriarán, Ricardo. 1968 en Compostela. 16 testemuños. Santiago de Compostela: Servizo de Publicacións da USC y Fundación 10 de Marzo, 2010. GURRIARÁN, RICARDO. Inmunda escoria. A universidade franquista e as mobilizacións estudantís en Compostela, 1939-1968. Vigo: Edicións Xerais, 2010.

GuRRIARÁN, RICARDO. "A Asociación de Cultura Iberoamericana da Coruña (ACI) e O Facho: cultura asociativa no franquismo, con Fraga na reboti-

\footnotetext{
${ }^{35}$ Entrevista grabada en Pontedeume (A Coruña), 1 de abril de 2007.

${ }^{36}$ Para más abundamiento ver Inmunda...; "El movimiento..."; 1968 en Compostela. 16 testemuños (Gurriarán, Santiago de Compostela, USC y Fundación 10 de Marzo, 2010) y Do "Gaudeamus igitur" ao "Venceremos nós". As mobilizacións estudantís do 68 en Compostela (Gurriarán, Santiago de Compostela, Fundación 10 de Marzo, 2008), catálogo de la exposición homónima, conmemorativa, comisariada por el autor. Razones de espacio impiden atender, en este artículo, el periodo posterior (1969-1975), caracterizado por la creciente movilización.
} 
ca". En A cultura e o asociacionismo cívico na Coruña. Entre a oficialidade e a resistencia, editado por Ricardo Gurriarán. A Coruña: Fundación 10 de Marzo y Concellería de Culturas do Concello da Coruña, 2019. GURRIARÁn, RiCARDo "El movimiento estudiantil en la Universidad Gallega. De la calma a la subversión". En Galicia en Transición, dirigido por Julio Prada. Madrid: Silex, 2019: 225-261.

HeIne, HaRTMUT. A guerrilla antifranquista en Galicia. Vigo: Edicións Xerais, 1980.

LizCANo, PABlo. La generación del 56. La Universidad contra Franco. Barcelona: Grijalbo, 1981.

PARís AMADOR, CARLos. Memorias sobre medio siglo. De la contrarreforma a internet. Barcelona: Península, 2006.

RodríGuez LAGo, José RAMón. La Iglesia en la Galicia del franquismo. Sada, A Coruña: Ediciós do Castro, 2005.

VV. AA. Documentos Inéditos para la Historia del Generalísimo Franco. Burgos: Azor/Fundación Nacional Francisco Franco, Tomo III, 1992. 